\title{
GINÁSTICA RÍTMICA: PERFIL SOBRE A PRODUÇÃO CIENTÍFICA EM PERIÓDICOS DA AMÉRICA LATINA, CARIBE E PAÍSES IBÉRICOS
}

\author{
RHYTHMIC GYMNASTICS: PROFILE ON SCIENTIFIC PRODUCTION IN \\ JOURNALS IN LATIN AMERICA, THE CARIBBEAN AND IBERIAN COUNTRIES
}

\section{GIMNASIA RÍTMICA: PERFIL SOBRE LA PRODUCCIÓN CIENTÍFICA EN REVISTAS CIENTÍFICAS DE AMÉRICA LATINA, CARIBE Y PAÍSES IBÉRICOS}

\author{
Leticia Cristina Lima Moraes ${ }^{1}$, Marcelo Moraes e Silva ${ }^{1}$, leda Parra Barbosa Rinaldi², \\ Jeferson Roberto Rojo'2, Leonardo do Couto Gomes ${ }^{1}$ \\ (1) Universidade Federal do Paraná (2) Universidade Estadual de Maringá
} Envio original: 2018-06-04. Reenviado: 2018-11-15, 2018-12-11. Aceitado: 2018-12-28.
Publicado: 2019-01-01

Doi: https://doi.org/10.15517/pensarmov.v17i1.33546

Resumo: A presente pesquisa visa mapear a produção do conhecimento sobre Ginástica Rítmica publicada em periódicos da América Latina, Caribe e países ibéricos. Para cumprir esse fim, foi escolhida a proposta de cunho exploratório descritivo, elencando-se artigos indexados nas seguintes bases de dados: Scielo, Lilacs e Medline acessados por meio da interface da Biblioteca Virtual da Saúde e Redalyc. Ao fim, o estudo encontrou 48 artigos publicados em 27 periódicos diferentes, distribuídos no período de 2001-2017. A temática que mais despertou interesse nos pesquisadores é relativa ao Treinamento, correspondendo a $41,67 \%$. Apesar do predomínio do referido eixo, encontrouse uma notória pluralidade epistemológica que contempla: saúde, aspectos psicológicos, aspectos educacionais e aspectos sociais, culturais e históricos. Conclui-se, portanto, a existência de um cenário auspicioso para uma área que pretende consolidar-se cientificamente, sendo necessária a crescente de estudos amparados nas demais maneiras de se abordar o esporte, ascendendo essas produções quantitativamente e qualitativamente.

Palavras chaves: Ginástica Rítmica; Produção do Conhecimento; Periódicos.

Abstract: The present research aims at mapping the production of knowledge about Rhythmic Gymnastics published in Latin American, Caribbean and Iberian journals. To fulfill this purpose, a descriptive exploratory proposal was chosen, listing articles indexed in the following databases: Scielo, Lilacs and Medline accessed through the interface of the Virtual Health Library and Redalyc. Finally, the study found 48 articles published in 27 different journals, distributed in the period 2001-2017. The theme that most aroused interest in researchers is related to Training, corresponding to $41.67 \%$. 
Despite the predominance of this axis, there was a notorious epistemological plurality that includes: health, psychological aspects, educational aspects and social, cultural and historical aspects. It is concluded, therefore, the existence of an auspicious scenario for an area that intends to consolidate scientifically, being necessary the growing of studies supported in the other ways of approaching the sport, ascending these productions quantitatively and qualitatively.

Keywords: Rhythmic Gymnastics; Knowledge Production; Journals.

Resumen: La presente investigación pretende mapear la producción del conocimiento sobre Gimnasia Rítmica publicada en periódicos de América Latina, Caribe y países ibéricos. Para cumplir este fin, se eligió la propuesta de cuño exploratorio descriptivo, enumerando artículos indexados en las siguientes bases de datos: Scielo, Lilacs y Medline accedidos por medio de la interfaz de la Biblioteca Virtual de la Salud y Redalyc. Al final, el estudio encontró 48 artículos publicados en 27 revistas científicas diferentes, distribuidos en el período de 2001-2017. La temática que más despertó interés en los investigadores es relativa al Entrenamiento, correspondiendo al 41,67\%. A pesar del predominio de dicho eje, se encontró una notoria pluralidad epistemológica que contempla: salud, aspectos psicológicos, aspectos educativos, y aspectos sociales, culturales e históricos. Se concluye, por lo tanto, la existencia de un escenario auspicioso para un área que pretende consolidarse científicamente, siendo necesaria la creciente de estudios amparados en las demás maneras de abordar el deporte, ascendiendo esas producciones cuantitativamente y cualitativamente.

Palabras claves: Gimnasia Rítmica; Producción del conocimiento; Revistas Científicas.

\section{Introdução}

Originada em meados de 1930, a Ginástica Rítmica (GR) atingiu sua regulamentação e reconhecimento pelo COI (Comitê Olímpico Internacional), mas como esporte olímpico apenas em 1984, e, consequentemente, sua primeira participação como modalidade competitiva somente nos Jogos de Los Angeles 1984 (Santos, Lorenço \& Gaio, 2010). Salienta-se que essa modalidade ginástica possui dois tipos de provas, as individuais e as de conjunto, e que em 1984 somente as provas individuais fizeram parte do programa dos Jogos Olímpicos, já as provas de conjunto só foram incluídas em 1996, nos Jogos Olímpicos de Atlanta (USA). Assim, entende-se que como esporte a GR é relativamente jovem, posto que se tornou modalidade olímpica há apenas três décadas. 
Com relação às competições, na atualidade, os países que mais se destacam mundialmente são os países da antiga União Soviética, Bulgária entre outros do leste europeu (Lourenço, 2015). Já o Caribe e os Países Ibero-Americanos só ganham notoriedade em esfera mundial nos Jogos Olímpicos de Barcelona em 1992, com uma medalha de prata espanhola no individual geral, e em Atlanta 1996, com o título olímpico nas provas de conjunto também da seleção hispânica. No caso da América Latina, Lourenço (2003) evidencia que somente a partir de 1999, nos XXII Jogos Pan Americanos em Winnipeg (Canadá), edição na qual o Brasil foi campeão, é que a região atingiu resultados significativos em âmbito internacional, acarretando em visibilidade da GR nessa parte do globo e, consequentemente, agregando praticantes em potencial à modalidade. A participação dos países caribenhos é até o presente momento simbólica, apesar de países como Cuba e Porto Rico também estarem presentes nas grandes competições mundiais. Nota-se, portanto, um cenário, de certa forma, promissor para o desenvolvimento da referida modalidade no contexto caribenho, latino e ibero americano, tornando importante evidenciar como a Ginástica Rítmica vem sendo pesquisada por pesquisadores destas localidades.

Nesse sentido, surge o interesse em investigar como essa modalidade esportiva vem sendo estudada na América Latina, Caribe e países ibéricos. Sendo assim, o presente artigo buscou responder à seguinte problemática de pesquisa: Qual o perfil da produção cientifica sobre Ginástica Rítmica em periódicos da América Latina, Caribe e países ibéricos? O objetivo geral consiste em traçar um panorama da produção científica escrita em periódicos da América Latina, Caribe e países ibéricos, sobre a modalidade Ginástica Rítmica. Já os objetivos específicos são: a) verificar o perfil temático das produções sobre Ginástica Rítmica na América Latina, Caribe e países ibéricos, b) evidenciar as autorias/coautorias e instituições, bem como suas redes de colaboração.

\section{Metodologia}

Para composição do escopo da pesquisa foram eleitos artigos indexados nas seguintes bases de dados: Scielo (Scientific Electronic Library Online), Lilacs (Literatura Latino-americana e do Caribe em Ciências da Saúde) e Medline (Medical Literature Analysis and Retrievel System Online) acessados por meio da interface da Biblioteca Virtual da Saúde (BVS-BIREME) e Redalyc (Red de Revistas Científicas de América Latina y el Caribe, España y Portugal). Bases essas selecionadas por apresentarem conteúdo abrangente em relação às indexações de diferentes 
periódicos, estes de diversificadas áreas do conhecimento, contemplando diferentes nações da América Latina, Caribe e países ibéricos.

Foram utilizados descritores em três idiomas: Espanhol, Inglês e Português. Os termos utilizados foram os seguintes: "Gimnasia rítmica", "Gimnasia Rítmica deportiva", "Sports Rhythmic Gymnastics", "Rhythmic Gymnastics", "Ginástica Rítmica", "Ginástica Rítmica desportiva". Em relação à temporalidade, a mesma não foi restringida, a fim de investigar as produções mais antigas sobre a temática, ou seja, foram selecionados artigos desde o primeiro ano encontrado nas bases elencadas, até agosto de 2017, período qual se realizou a coleta dos materiais, restringindo, portanto, o presente estudo ao recorte temporal de 2001 à 2017. No que se refere a exclusão, os artigos duplicados e/ou encontrados em mais de uma base de dados foram considerados apenas uma vez, totalizando ao final 48 artigos.

A catalogação foi realizada em uma planilha eletrônica e utilizou-se das seguintes informações contidas nos artigos: a) autores; b) país da instituição; c) ano de publicação; d) revista; e) temática central do artigo. As informações relacionadas aos autores não localizadas no próprio artigo foram coletadas no Currículo Lattes $^{1}$ e nas páginas online das universidades às quais se vinculam os pesquisadores. Tornase importante salientar a vulnerabilidade da catalogação nas informações de alguns autores, visto que não estão cadastrados em plataformas de fácil acesso, dificultando a obtenção de suas informações profissionais.

A fim de identificar os enfoques temáticos dos artigos, realizou-se leitura preliminar e/ou completa dos trabalhos para posteriormente, baseando-se em estudo de Souza, Moraes e Silva e Moreira (2016), organizá-los em categorias que agrupassem os temas encontrados. Para tanto, a classificação em mais de um eixo foi necessária, tendo em vista a correspondência simultânea de determinados trabalhos com diferentes temáticas. Os artigos encontrados foram classificados dentro dos seguintes eixos temáticos:

- Treinamento: espaços e equipamentos relacionados à performance, aspectos motores, fisiológicos, técnicos, táticos e biomecânicos relacionados ao rendimento;

- Iniciação Esportiva e Categorias de Base: metodologia de ensino, aprendizagem motora, treinamento de jovens atletas e seleção de talentos esportivos;

-Saúde: promoção, manutenção e reabilitação da saúde, lesões e patologias;

1 A Plataforma Lattes representa experiência na integração de bases de dados de Currículos, de Grupos de pesquisa e de Instituições em um único sistema de informações. O Currículo Lattes, portanto, é um padrão brasileiro de registro de informações dos estudantes e pesquisadores do referido país, adotado pela maioria das instituições de fomento, universidades e institutos de pesquisa do Brasil. 
- Aspectos Sociais, Culturais e Históricos do Esporte: aspectos sociológicos, antropológicos e históricos relacionados com ao esporte (discussões sobre temáticas tais como gênero, mídia, marketing, violência, valores, etc.);

- Aspectos Nutricionais: perfil dietético e suplementação alimentar.

Para a exposição dos resultados da pesquisa, primeiramente apresenta-se os números gerais, especificando a quantidade de publicações sobre a Ginástica Rítmica cronologicamente e sua distribuição nos periódicos. Em seguida evidenciam-se os autores e instituições com maior produtividade, e, por fim, ocorre um detalhamento dos assuntos abordados em cada um dos eixos temáticos.

\section{Resultados e discussões}

Com base nos dados levantados, a seguir apresenta-se a distribuição dos 48 artigos encontrados durante a periodicidade constatada (2001-2017), conforme o gráfico abaixo:

\section{Tabela 1}

Número de artigos publicados por ano - Sistematizado pelos autores.

\begin{tabular}{ccc}
\hline Ano & Total & $\%$ \\
\hline 2001 & 1 & $2,08 \%$ \\
\hline 2005 & 1 & $2,08 \%$ \\
\hline 2006 & 3 & $6,25 \%$ \\
\hline 2007 & 1 & $2,08 \%$ \\
\hline 2009 & 3 & $6,25 \%$ \\
\hline 2010 & 4 & $8,33 \%$ \\
\hline 2011 & 2 & $4,17 \%$ \\
\hline 2012 & 7 & $14,58 \%$ \\
\hline 2013 & 6 & $12,50 \%$ \\
\hline 2014 & 5 & $10,42 \%$ \\
\hline 2015 & 6 & $12,50 \%$ \\
\hline 2016 & 8 & $16,67 \%$ \\
\hline 2017 & 1 & $2,08 \%$ \\
\hline
\end{tabular}

O ano de 2016 foi o ano com maior número de publicações, correspondendo a $16,67 \%$ (oito artigos), logo em seguida aparece o de 2012 com sete artigos, e 2013 e 2015, ambos com um total de seis publicações. Como se pode observar, existe uma lacuna entre os anos 2001 e 2005, períodos que também apresentam baixa produção acerca da modalidade. Contudo, a distribuição é relativamente proporcional em cada 
ano, atingindo uma crescente a partir do ano de 2012. Em relação à baixa produção constatada em 2017, pressupõe-se o atraso nas publicações de seus volumes, comprometendo a cronologia da publicação e/ou o caso dos periódicos ainda não disponibilizarem seus artigos nessas bases até o período final da catalogação.

Para evidenciar as publicações e a distribuição dessas nos periódicos em questão, a tabela a seguir mostra a quantidade de artigos publicados por cada revista:

Tabela 2

Revistas que publicaram artigos sobre ginástica rítmica - Sistematizado pelos autores

\begin{tabular}{ccc}
\hline REVISTA & PAís & $\begin{array}{c}\text { NÚMERO DE } \\
\text { ARTIGOS }\end{array}$ \\
\hline $\begin{array}{c}\text { Revista Brasileira de Educação Física e Esporte } \\
\text { Revista Brasileira de Medicina do Esporte }\end{array}$ & Brasil & 6 \\
\hline Revista Brasileira de Ciência e Movimento & Brasil & 4 \\
\hline Pensar a Prática & Brasil & 3 \\
\hline Revista Brasileira de Ciências do Esporte & Brasil & 2 \\
\hline Motriz & Brasil & 2 \\
\hline International Journal of Morphology & Chile & 2 \\
\hline Acta Scientiarum Health Sciences & Brasil & 2 \\
\hline Revista da Educação Física (Uem. Online) & Brasil & 2 \\
\hline Fitness e Performance Journal & Brasil & 2 \\
\hline Revista Andaluza de Medicina del Deporte & Espanha & 2 \\
\hline Total Geral & & 32 \\
\hline
\end{tabular}

Na tabela 1 estão os 11 periódicos que publicaram mais de um artigo sobre a temática; 16 periódicos publicaram somente um artigo. A Revista Brasileira de Educação Física e Esporte possui a maior quantidade de manuscritos, contabilizado seis artigos. Na sequência, a Revista Brasileira de Medina do Esporte com cinco textos, a Revista Brasileira de Ciência e Movimento com quatro manuscritos e a revista Pensar a Prática com três artigos. Em seguida aparecem os periódicos com apenas dois artigos em suas páginas: Revista Brasileira de Ciências do Esporte, Motriz, International Journal of Morphology, Acta Scientiarum Health Sciences, Revista da Educação Física, Fitness e Performance Journal e Revista Andaluza de Medicina del Deporte. 
Torna-se importante salientar que desse total de 27 revistas, sete são espanholas com total de oito publicações referentes ao tema (Journal of Human Sport and Exercise, Nutrición Hospitalaria, Revista de Investigacion, Motricidad. European Journal of Human Movement, Revista de Psicologia del Deporte, Revista Iberoamericana de Psicología del Ejercicio y el Deporte, Revista Andaluza de Medicina del Deporte). Apenas uma é colombiana com um estudo (Revista de Salud Publica), uma mexicana com um artigo (Ra Ximhai) e uma chilena com duas publicações (International Journal of Morphology). Revistas essas, que contabilizam ao todo 12 manuscritos sobre a modalidade, enquanto as revistas brasileiras (17) compõem-se de 36 textos, evidenciado a predominância do Brasil em relação à quantidade de periódicos e publicações.

Essa discrepância a respeito das produções, também pode ser notada ao observar as quais instituições os autores estavam vinculados e suas respectivas nacionalidades, conforme indica o gráfico abaixo:

\section{Tabela 3}

Países das instituições, às quais os autores que produziram sobre a GR estavam vinculados (de acordo com informações retiradas do próprio artigo/plataformas online).

\begin{tabular}{ccc}
\hline $\begin{array}{c}\text { PAÍS DA } \\
\text { INSTITUIÇÃO }\end{array}$ & TOTAL & $\%$ \\
\hline Brasil & 35 & $66,04 \%$ \\
\hline Espanha & 8 & $15,09 \%$ \\
\hline Venezuela & 2 & $3,77 \%$ \\
\hline Portugal & 2 & $3,77 \%$ \\
\hline Mexico & 1 & $1,89 \%$ \\
\hline França & 1 & $1,89 \%$ \\
\hline Cuba & 1 & $1,89 \%$ \\
\hline Canada & 1 & $1,89 \%$ \\
\hline Chile & 1 & $1,89 \%$ \\
\hline Estados Unidos & 1 & $1,89 \%$ \\
\hline & &
\end{tabular}

O Brasil apresenta um número significativo de instituições com vinculação dos pesquisadores que publicaram sobre o tema, contabilizando 35 instituições (66,04\%). Em seguida, a Espanha com oito instituições, Portugal apresentou dois estudos, assim como a Venezuela. Com apenas uma instituição, aparecem os seguintes países: França, Cuba, México, Canadá, Chile e Estados Unidos.

A França, o Canadá e os Estados Unidos, países localizados fora da delimitação espacial estabelecida para este artigo, possuem autores vinculados a uma instituição cada, porém a publicação de seus trabalhos sobre a Ginástica Rítmica foi realizada em revistas brasileiras. Com publicação na Revista Brasileira de Educação 
Física e Esporte, a pesquisadora Monique Loquet, é ligada à Universidade de Rennes, na França (Loquet, 2016). O brasileiro Marcos Alencar Abaide Balbinotti, coautor do texto publicado na revista Pensar a Prática, é docente vinculado à Universidade do Quebec em Trois-Rivières - Canadá (Fontana, Barbosa, Balbinotti \& Balbinotti, 2013). Por fim, a Revista Brasileira de Ciência e Movimento tem em suas páginas 0 manuscrito da também brasileira Priscila Martins Caçola, vinculada à Texas A\&M University, localizada nos Estados Unidos (Caçola \& Ladewig, 2007).

A próxima análise discorre sobre os autores e coautores que mais produziram sobre a modalidade.

\section{Tabela 4}

Top 6 autores e coautores com mais de uma Publicação - Sistematizado pelos autores.

\begin{tabular}{ccc}
\hline Autores & Número de Artigo & Países dos Autores \\
\hline Lenamar Fiorese Vieira & 4 & Brasil \\
Luciana de Souza Menezes & 3 & Brasil \\
Rodrigo Franco de Oliveira & 3 & Brasil \\
Andre Wilson de Oliveira Gil & 3 & Brasil \\
Jose Fernandes Filho & 3 & Brasil \\
Jose Luiz Lopes Vieira & 3 & Brasil \\
\hline
\end{tabular}

Lenamar Fiorese é a pesquisadora com o maior número de artigos publicados. A referida autora é docente da Universidade Estadual de Maringá, instituição na qual atua também como professora do Programa de Pós-Graduação Associado em Educação Física - Universidade Estadual de Maringá/Universidade Estadual de Londrina. As linhas de pesquisas desenvolvidas pela pesquisadora são as seguintes: aprendizagem e desenvolvimento motor, aspectos psicopedagógicos da Educação Física e do Esporte, esporte e desempenho motor. Sua forma de abordar o objeto de pesquisa é herdada de sua formação advinda de suas graduações em Educação Física em 1982 e Psicologia em 2010. A mesma possui mestrado (1993) e doutorado (1999) em Educação Física. Além de sua carreira acadêmica, é imprescindível mencionar sua relação direta com a esfera da GR, visto que desde de 2000 é assessora da seleção brasileira da modalidade, vínculo esse que pode ter repercutido na predominância de suas produções sobre o tema, publicando um manuscrito em cada um dos seguintes periódicos: Acta Scientarum Health Sciences (Vieira, Botti \& Vieira, 2005), Motriz (Vieira, Vieira, Amorim, Amorim \& Rocha, 2009), Revista 
Brasileira de Medicina do Esporte (Vieira, Vieira, Amorim, Amorim \& Rocha, 2009) e Pensar a Prática (Nakashima, Nascimento Junior \& Vieira, 2012).

Na sequência aparece Luciana de Souza Menezes, com três artigos. Mestre pela Universidade Castelo Branco em 2004 e doutora em Ciências do Desporto pela Universidade de Trás-os-Montes e Alto Douro, Portugal (2012), tem uma trajetória estreita com o esporte. Sua dissertação versa sobre aspectos biológicos de atletas de GR e a tese sobre o perfil morfológico de ginastas. Atualmente é professora adjunta do Instituto de Educação Física e Desportos da Universidade do Estado do Rio de Janeiro. Seus artigos encontram-se nas seguintes revistas: Fitness e Performance Journal (Menezes \& Fernandes Filho, 2006), Revista de Salud Publica (Menezes, Novaes \& Fernandes Filho, 2012), International Journal of Morphology (Menezes, Novaes \& Fernandes Filho, 2014).

O professor José Fernandes Filho possui mestrado, obtido em 1989 na Universidade de Ribeirão Preto e doutorado também em Educação Física pelo Instituto de Investigação Científica de Cultura Física e Esportes da Rússia, em 1997. O pesquisador é vinculado à Escola de Educação Física e Desporte da Universidade Federal do Rio de Janeiro e do Programa de Pós-Graduação em Educação Física da mesma instituição. O mesmo também produziu três artigos juntamente com Luciana de Souza Meneses, que foi sua orientanda de mestrado.

Também com três artigos aparece Rodrigo Franco de Oliveira. O investigador é graduado em Fisioterapia pela Faculdade Claretiana de Batatais (1988), mestre em Educação Física pela Universidade Católica de Brasília (2001) e doutor em Engenharia Biomédica pela Universidade do Vale do Paraíba (2008). Atualmente é docente do Centro Universitário de Anápolis, e membro da comissão à qual se incumbiu a elaboração e implantação do Curso de Pós Graduação Stricto Sensu e Mestrado Profissional em Exercício Físico na Promoção de Saúde, na área de Educação Física, da Universidade Norte do Paraná. As respectivas produções são resultado de coautorias, contabilizando um texto em cada uma das seguintes revistas: Unopar Cientifica Ciências Biológicas e da Saúde (Guiotte et al, 2012), na Revista Brasileira de Medicina do Esporte (Lamb et al., 2014) e na revista Conscientiae Saúde (Hirata \& Oliveira, 2015).

O pesquisador André Wilson de Oliveira Gil, tem coautoria em três artigos, dois deles juntamente com Rodrigo Franco de Oliveira e de mais um na Revista Brasileira de Medicina do Esporte (Shigaki et al., 2013). Gil é graduado pela Universidade Norte do Paraná (2011) e mestre (2014) em Fisioterapia (Unopar). Atualmente é doutorando no Programa da Educação Física UEM/UEL. 
O último pesquisador com três manuscritos é José Luiz Lopes Vieira. Possui mestrado (1993) e doutorado (1999) pela UFSM em Educação Física. Vieira é professor da Universidade Estadual de Maringá e do Programa de Pós-Graduação em Educação Física UEM/UEL. Suas linhas de pesquisa são relacionadas ao desenvolvimento motor e psicologia do esporte e do exercício físico. Atualmente é Editor do Journal of Physical Education (antiga Revista da Educação Física/UEM). Quanto aos trabalhos acerca da modalidade, foram produtos de pesquisas coletivas realizadas com Lenamar Fiorese Vieira. Os artigos publicados na revista Motriz (Vieira, Vieira, Amorim, Amorim \& Rocha, 2009) e na Revista Brasileira de Medicina do Esporte (Vieira, Vieira, Amorim, Amorim \& Rocha, 2009) e na Acta Scientarum Health Sciences (Vieira, Botti \& Vieira, 2005).

Ao analisar as autorias e coautorias é perceptível uma intensa rede de colaboração, visto que os autores que possuem a maior quantidade de artigos sobre a GR os produzem conjuntamente. No gráfico abaixo, pode-se ilustrar essa tendência de produção em parceria:

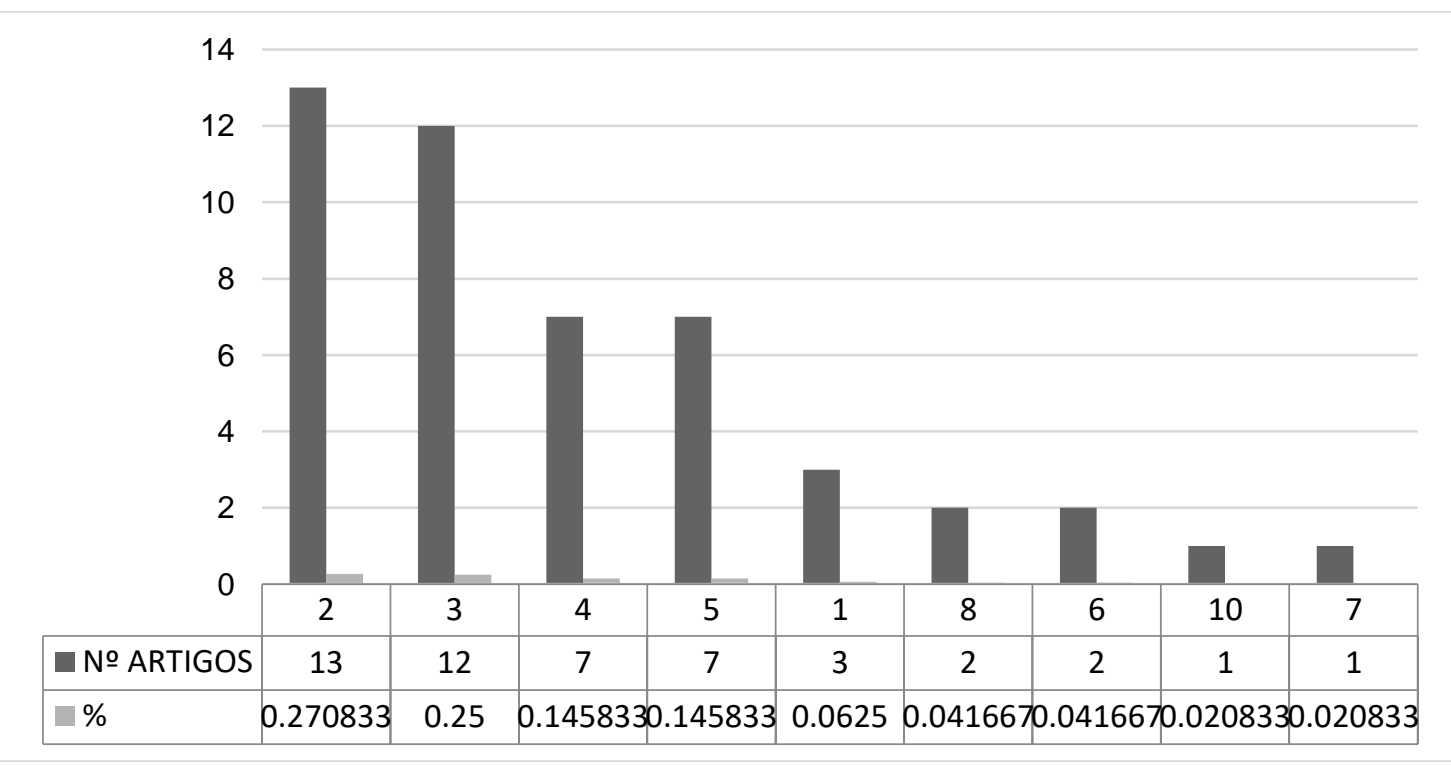

Figura 1: Número de autores e coautores por artigo - Sistematizado pelos autores

Foram encontrados somente três artigos com um único autor, sendo 6,25\% de todos os manuscritos catalogados, e os mesmos são de autorias diferentes. A predominância da rede de colaboração entre pesquisadores nos artigos é notável, visto que 13 produções foram realizadas por dois autores, em seguida, 12 escritos por três pesquisadores. Com quatro autores há a correspondência de sete manuscritos, assim como a associação de cinco colaboradores que também contabilizam sete. Dois 
textos com oito autores, e outros dois com seis envolvidos. Por fim, tem-se um artigo com seis membros, e outro contendo a participação de 10 pesquisadores. Essa tendência em publicar de forma conjunta pode ser explicada, segundo aponta Garcia et al. (2010), por um maior status, custeamento de pesquisas e legitimação dentro do meio acadêmico. Afinal a materialização de um capital nessa esfera acontece através da produção científica, ou seja, a forma, portanto, mais recorrente de obter uma eficiência dessa produtividade advém da parceria entre pesquisadores, principalmente das denominadas coautorias.

Leta e Cruz (2003), indicam que as coautorias podem ser indiciadoras de associação cientifica entre países, instituições e pesquisadores. Segundo Garcia et al. (2010) esses cientistas visam diversos e complexos propósitos, que vão além da expansão do conhecimento científico, pois permitem que o pesquisador possa ter sua produção avaliada, visto que a autoria é usada como critério para a concessão de recursos pelas agências de fomento, além de ser uma ferramenta de avaliação dos cursos de pós-graduação e um parâmetro para a seleção de corpo docente e da equipe de pesquisa. Evidencia-se que nas pesquisas referentes à GR está presente essa rede de colaboração, em que diversos autores - principalmente os que mais produziram - utilizam-se dessa estratégia no seu fazer científico.

A diversidade epistemológica no fazer científico sobre GR é manifestada nas temáticas abordadas e classificadas, conforme aponta a tabela a seguir:

\section{Tabela 5}

Quantidade de artigos por eixos temáticos: Sistematizados pelos autores.

\begin{tabular}{ccc}
\hline TEMÁTICA DO ARTIGO & TOTAL & $\%$ \\
\hline Treinamento & 20 & $41,67 \%$ \\
\hline Saúde & 4 & $8,33 \%$ \\
\hline Iniciação esportiva e categorias de base & 4 & $8,33 \%$ \\
\hline Aspectos nutricionais & 4 & $8,33 \%$ \\
\hline Saúde/treinamento & 4 & $8,33 \%$ \\
\hline Aspectos psicológicos & 4 & $8,33 \%$ \\
\hline Aspectos educacionais & 3 & $6,25 \%$ \\
\hline Aspectos sociais, culturais e históricos & 3 & $6,25 \%$ \\
\hline Aspectos psicológicos/treinamento & 2 & $4,17 \%$ \\
\hline Total geral & 48 & $100,00 \%$ \\
\hline
\end{tabular}

O eixo Treinamento foi o mais recorrente, totalizando 20 artigos $(41,67 \%)$. Saúde (8,33\%), Iniciação Esportiva e Categorias de Base (8,33\%), Aspectos Nutricionais (8,33\%) e artigos classificados em Saúde/Treinamento $(8,33 \%)$ cada um 
com quatro artigos, intensificam a preeminência epistemológica das Ciências Naturais, totalizando 74,99\%. As demais temáticas: Aspectos Psicológicos contendo quatro manuscritos (8,33\%), Aspectos Educacionais com três (6,25\%), Aspectos Sociais, Culturais e Históricos contabilizado também com três escritos $(6,25 \%)$ e Aspectos psicológicos/Treinamento apresentando dois trabalhos $(4,17 \%)$, esses que contemplam especificidades da psicologia em prol da melhora da performance. Ao total, soma-se $25 \%$ da produção encontrada.

Ao analisar os dados, é perceptível a inclinação dos estudos às Ciências Naturais, visto que, em periódicos da área de Educação Física existe uma tendência de publicações estarem ligadas às vertentes biológicas, afirmação constatada em estudos anteriores de Manoel e Carvalho (2011) e Rigo, Ribeiro e Hallal (2011). A predisposição confere com a tradição epistemológica da área de Educação Física próxima das Ciências Biológicas, corroborando com o número superior de pesquisadores dessa área e, consequentemente, à superioridade em número de periódicos e publicações em relação às Ciências Humanas.

O eixo Treinamento apresenta abordagens acerca da preparação física e aptidão física das atletas de Ginástica Rítmica, versa sobre características e qualidades físicas/biológicas/fisiológicas das atletas, análises de equilíbrio, maturação biológica e métodos de treinamento, sobre a influência da flexibilidade e do treino de força na execução dos movimentos característicos da modalidade, e analisa a promoção da qualidade artística na GR tanto no treinamento de alta performance quanto na prática escolar. Assim, em sua totalidade, observou-se que na categoria de treinamento a frequência de análise acerca de exercícios para força e flexibilidade foram evidentes, além de constar proposta de protocolo ou metodologia nas pesquisas para o tipo de treinamento.

A título de exemplo destaca-se o estudo de Ramos e Velásquez (2006), aonde os autores elaboraram um sistema de orientações metodológicas para a preparação física (força) específico para a modalidade da GR, composto por três grupos fundamentais de exercícios: preparação geral, tendo o circuito como principal exemplo; os exercícios auxiliares; e os específicos. No estudo esmiunça-se os benefícios do treinamento de força, além de fornecer subsídio para a realizar a preparação, demonstrando quão eficaz foi seu protocolo. Para o treinamento de flexibilidade, o estudo de Karloh et al (2006) realizou testes em que o Grupo 1 que treinou com o método Mulligan (Long Leg Traction) obteve ganhos estatisticamente significativos superiores que o Grupo 2 que usou o alongamento estático. Para complementar e reafirmar a importância que alguns estudos que compõem esse eixo dão ao treinamento de força e flexibilidade Silva et al (2016) com uma intervenção 
composta por exercícios específicos concluiu que o trabalho específico de força e flexibilidade pode influenciar de forma positiva no treinamento de GR, especialmente nos saltos, que demandam uma boa elevação do corpo, além de atingir amplitude de movimento no período de voo. Portanto, percebe-se uma inclinação dos artigos em verificar possíveis relações do melhoramento de determinadas capacidades físicas e/ou habilidades motoras na performance de praticantes da modalidade.

Esses 20 artigos são encontrados nos seguintes periódicos: Fitness $e$ Performance Journal (Penedo, Beltrão \& Nunes, 2006; Menezes \& Fernandes Filho, 2006) Ra Ximhai (Mena-Ramos \& Álvarez-Velásquez, 2006) Revista Brasileira de Cineantropometria e Desempenho Humano (Karloh, Petry, Kraeski, Matias \& Frutuoso, 2010), Arquivos de Ciências da Saúde da Unipar (Gonçalves, Barros Filho \& Gonçalves, 2010), Motricidad. European Journal of Human Movement (Vernetta, Fernández, López-Bedoya, Gómez-Landero \& Oña, 2011), Revista Brasileira de Ciência e Movimento (Pinto Júnior, Sousa, Gaya \& Alves, 2012; Del Vecchio, Primeira, Silva, Dall'agnol \& Galliano, 2014), Revista de Salud Publica (Souza Menezes, Novaes \& Fernandes-Filho, 2012), Revista Brasileira de Medicina do Esporte (Perin, Ulbricht, Ricieri \& Neves, 2012; Shigaki et al., 2013), Journal of Human Sport and Exercise (Bobo-Arce \& Méndez-Rial, 2013), Revista Brasileira de Educação Física e Esporte (Goulart, Dias, Lemos, Oliva, Lanferdini \& Vaz, 2014; Santos, Lebre \& Carvalho, 2016; Loquet, 2016), International Journal of Morphology (Menezes, Novaes \& Fernandes-Filho, 2014; Arriaza, Rodríguez, Carrasco, Mardones, Niedmann \& López-Fuenzalida, 2016), Revista Andaluza de Medicina del Deporte (GuimaraesRibeiro, Hernández-Suárez, Rodríguez-Ruiz \& García-Manso, 2015), Acta Scientarum Health Sciences (Boligon, Deprá, \& Rinaldi, 2015) e Revista Saúde e Pesquisa (Silva, Oliveira, Leme, Nascimento Júnior \& Anversa, 2016).

Os quatro escritos classificados no eixo Saúde contam com estudos sobre: avaliação física funcional, histórico e análise de lesões, desequilíbrios hormonais em atletas da GR e análise dos aspectos nutricionais, antropométricos e psicológicos em ginastas da modalidade. As lesões mais recorrentes analisadas foram musculares e tendinosas, com a predominância de dores nas costas - aspecto que deve ser levado em consideração para melhorar a prevenção. Portanto, no que se diz respeito a este eixo temático, nota-se uma tendência por parte dos pesquisadores em se utilizar da modalidade aqui estudada como ferramenta para análises de fatores que não condizem diretamente com o momento do treinamento e da competição, mas com as condições que regulam a manutenção física do praticante.

Essas pesquisas se encontram nas revistas: Unopar Científica Ciências Biológicas e da Saúde (Guiotte et al., 2012), Revista Brasileira de Ciências do Esporte 
(Coelho, Simões \& Lunz, 2015), Revista Andaluza de Medicina del Deporte (Vernetta, Montosa \& Lopez-Bedoya, 2016), Nutrición Hospitalaria (San Mauro Martin, Cevallos, Pina Ordunez \& Garicano Vilar, 2016).

Com quatro artigos, a classificação Iniciação Esportiva e Categoria de Base contempla os seguintes assuntos: estudo de revisão sobre a detecção e seleção de talentos esportivos na GR, a comparação de métodos na aprendizagem de uma habilidade específica da modalidade e efeitos do feedback no treinamento, e por fim, a investigação da influência dos programas de iniciação esportiva no desempenho e desenvolvimento de habilidade para a maestria. Lanaro Filho e Böhme (2001) abordam a necessidade de caracterizar cineantropometricamente as ginastas de alto rendimento em diferentes faixas etárias, com a finalidade de se obter indicadores, que possam servir de referenciais para se estimar quais as reais chances das ginastas iniciantes alcançarem o alto nível de desempenho esportivo - e não mais basear-se em escolhas subjetivas sem base científica. Neste eixo temático, encontrou-se uma predisposição pelos investigadores em utilizar-se da iniciação esportiva para detectar talentos, averiguar a evolução técnica, tática e física dos jovens praticantes nas mais variadas idades. Esses estudos encontram-se na Revista Brasileira de Educação Física e Esporte (Lanaro Filho \& Böhme, 2001; Lemos, Chiviacowsky, Avila \& Drews, 2013), Revista Brasileira de Ciência e Movimento (Caçola \& Ladewig, 2007) e Revista da Educação Física/UEM (Sampaio \& Valentini, 2015).

A temática Aspectos Nutricionais, também com um total de quatro manuscritos, explora predominante estudos sobre distúrbios alimentares e suas consequências, influência no crescimento físico das ginastas, distorção de imagem corporal em competições, estudo da composição corporal e risco de transtorno de conduta alimentar em atletas da modalidade do estado de Carabobo (Venezuela). A abordagem diferencial foi acerca da utilização de bebida artesanal como forma de suplementação em atletas da GR.

Por ser uma modalidade que sua eficiência depende, de certo modo, de um baixo peso, muitas atletas acabam desenvolvendo um desequilíbrio entre ingestão de nutrientes e exercício físico, além de possível risco de desordem de comportamento alimentar. Aqui identifica-se que é unânime entre os interessados em estudar o respectivo eixo a preocupação para com o impacto que os hábitos nutricionais geram no desenvolvimento e composição corporal das ginastas. Os artigos se materializaram na Revista Brasileira de Medicina do Esporte (Vieira, Vieira, Amorim, Amorim \& Rocha, 2009), Motriz (Vieira, Vieira, Amorim, Amorim \& Rocha, 2009), Salus (Palacios De Espig \& Jaeger, 2016) e na Revista Brasileira de Ciências do Esporte (Costa et al., 2017). 
Os artigos enquadrados tanto no eixo de Saúde como no de Treinamento, obtiveram essa classificação por apresentarem assuntos com a finalidade de melhora de performance, mas com um viés de tratamento e prevenção de futuras lesões. Contém os manuscritos que remetem à análise postural das atletas como medida preventiva e de auxílio para melhor desenvolvimento dos movimentos e importante como medida profilática para identificar os possíveis desalinhamentos posturais e prevenir alterações posturais que possam vir a acontecer, análise de equilíbrio e como as lesões decorrentes da demanda das alterações posicionais do membro inferior podem ser evitadas, além de pesquisas a respeito do treinamento proprioceptivo e seus efeitos na prevenção de lesões de ginastas. Percebe-se que, de forma geral, os pesquisadores interessados nestas discussões utilizam-se dos fatores voltados a saúde como meios de impulsionar a performance durante 0 treinamento $\mathrm{e}$ competições. Tais escritos estão na Revista Brasileira de Medicina do Esporte (Bosso \& Golias, 2012; Lamb et al., 2014), Revista Brasileira de Ciência e Movimento (Golias, 2012), e na Conscientiae Saúde (Hirata \& Oliveira, 2015).

A temática Aspectos Psicológicos contempla artigos que versam sobre fatores motivacionais compostos pelo gosto pela prática, estabelecimento de metas e estressantes condizentes com o baixo rendimento escolar, discordâncias e conflitos, falta de tempo para divertimento presentes no âmbito competitivo e na arbitragem. A participação e influência dos pais na carreira esportiva, e a avaliação e análise de habilidades psicológicas presentes em atletas da ginástica rítmica também fizeram parte do escopo. Nesta temática nota-se uma propensão por parte dos investigadores em pesquisar como determinadas características psicológicas influenciam na formação dos praticantes da referida modalidade. Tais textos pertencem aos seguintes periódicos: Acta Scientarum Health Sciences (Vieira, Botti \& Vieira, 2005), Revista Iberoamericana de Psicología del Ejercicio y el Deporte (Sanchez, Marquez \& Peralto, 2010), Pensar a Prática (Nakashima, Nascimento Junior \& Vieira, 2012), Revista da Educação Física/UEM (Debien, Noce, Debien \& Costa, 2014).

Os Aspectos Educacionais englobam assuntos referentes à formação profissional das técnicas/professoras de GR e a ginástica rítmica como conteúdo escolar. De forma geral, tais artigos buscam enfatizar a importância da formação de bons profissionais para o desenvolvimento esportivo, assim como uma necessidade de maior contato por parte dos estudantes com a modalidade no âmbito escolar. Os estudos estão nas páginas da revista Motriz (Belão, Machado \& Mori, 2009), Pensar a Prática (Oliveira \& Porpino, 2010), Revista Internacional de Medicina y Ciencias de la Actividad Física y el Deporte (Amengual \& Lleixà, 2011). 
Os três artigos com foco temático em Aspectos Sociais, Culturais e Históricos trazem em si as análises dos códigos de pontuação de GR, evidenciando mudanças históricas das técnicas e dos aspectos artísticos. Também apresenta um estudo que investiga as relações entre beleza, sofrimento e dor na ginástica rítmica, numa perspectiva filosófica. Evidencia-se que os trabalhos do referido eixo, se debruçam a entender como se deu a construção histórica da referida modalidade por diversas vias socioculturais. Os escritos estão vinculados à Revista de Investigacion (Mejías \& Maria, 2013), Holos (Cavalcanti \& Porpino, 2015) e a Revista Brasileira de Educação Física e Esporte (Toledo \& Antualpa, 2016).

Publicados na revista Pensar a Prática (Fontana, Barbosa, Balbinotti \& Balbinotti, 2013) e na Revista de Psicologia del Deporte (Álvarez, Falco, Estevan, Molina-García \& Castillo, 2013), os artigos vinculados tanto ao eixo Aspectos Psicológicos como ao Treinamento tratam de assuntos relacionados às contribuições da motivação ao rendimento e análise da intervenção de psicólogos em uma equipe de ginástica rítmica. Tais estudos buscam relacionar os possíveis benefícios de intervenções motivacionais com o rendimento durante o treinamento das praticantes de Ginástica Rítmica.

Embora as pesquisas sejam predominantes no eixo Treinamento, é incontestável a diversidade existente no material analisado. Esse fato ocorre devido à contribuição de inúmeros pesquisadores da Educação Física que transitam em outras áreas, e estudiosos de áreas distintas que se dedicam a explorar aspectos relacionados ao esporte.

\section{Considerações Finais}

O presente artigo buscou traçar o perfil da produção científica sobre Ginástica Rítmica contidos nos periódicos da América Latina, Caribe e países ibéricos. Esse conjunto de países foi escolhido devido ao crescente desenvolvimento da modalidade. Torna-se pertinente a realização do estudo na referida área geográfica pelo fato de que se comparado aos países hegemônicos na modalidade (Rússia, Bulgária, Ucrânia Bielorrússia e Itália), as nações da América Latina, Caribe e ibéricos vêm aos poucos ganhando espaço no cenário competitivo. Nesse sentido, analisar como a Ginástica Rítmica vem se desenvolvendo no universo científico na respectiva delimitação espacial se torna importante para poder fomentar maiores discussões acerca da prática, contribuindo diretamente no incentivo para que pesquisadores interessados neste objeto iniciem novas pesquisas. 
Com isto, buscou-se identificar como a modalidade foi estudada pelos pesquisadores na periodicidade delimitada entre os anos de 2001 a 2017. Torna-se pertinente advertir sobre as limitações práticas do estudo apresentado, uma vez que foram utilizados somente artigos publicados em periódicos latino-americanos, caribenhos e de países ibero-americanos. Ainda mais se considerar a comunidade científica em um contexto em que a internacionalização é algo incontestável e que a utilização de bases de dados mais abrangentes alteraria a metodologia e resultados da pesquisa. Logo, entende-se que um novo desenrolar para pesquisas neste cunho, são possíveis comparações entre os achados acerca da modalidade nas mais distintas localidades, bem como um olhar para outros produtos, como por exemplo, as dissertações e teses. Outra recomendação diz respeito a elaboração de novas categorias temáticas, afinal para este utilizou-se o olhar de outros pesquisadores, entende-se, portanto, que com novas perspectivas poderão emergir novos eixos temáticos.

Ao fim, o estudo encontrou 48 artigos publicados em 27 periódicos diferentes, dos quais 17 são brasileiros (total de 36 estudos), sete espanhóis (com oito manuscritos), um chileno com dois textos, e as revistas colombiana e mexicana com um artigo cada. Dessas, tem predominância de publicações a Revista Brasileira de Educação Física e Esporte com seis manuscritos, a Revista Brasileira de Medicina do Esporte com cinco, a Revista Brasileira de Ciência e Movimento com quatro, e a Pensar a Prática contendo três escritos. As outras 26 revistas contavam com um ou dois artigos cada. A temática que mais despertou interesse nos pesquisadores é relativa ao Treinamento, correspondendo a $41,67 \%$ de toda a produção científica encontrada sobre a GR.

Apesar do predomínio do referido eixo, é notória a pluralidade epistemológica no fazer ciência sobre Ginástica Rítmica na América Latina, Caribe e países ibéricos, visto que foi contemplada por diversificados enfoques epistemológicos. Mostra-se, portanto, um cenário auspicioso para uma área que pretende consolidar-se cientificamente. Sendo necessária a crescente de estudos amparados nas demais maneiras de se abordar o esporte, ascendendo essas produções quantitativamente e qualitativamente. Sinaliza-se aqui a importância prática deste trabalho, afinal acreditase que com o mesmo é possível a emergência de novos estudos nos mais variados eixos temáticos, inclusive com perspectivas epistemológicas distintas das localizadas nestes estudos.

Em relação ao modelo de produção dos artigos, constatou-se a existência da rede de colaboração de autores através do número de autores/instituições que cooperaram entre si. Tendência esta já evidenciada em estudos anteriores de Garcia 
et al. (2010) como próspera para os pesquisadores e para o âmbito científico. No que se refere ao país da instituição em que os autores estavam vinculados, o Brasil apresentou superioridade, contabilizando 35 instituições. Em seguida a Espanha com oito instituições e Portugal e Venezuela apresentaram duas cada. Com apenas uma instituição associada, os países: França, Cuba, México, Canadá, Chile e Estados Unidos. Observa-se que o fato da maioria dos estudos serem do Brasil e da Espanha possa ter uma direta relação desses serem os países dentro da delimitação espacial com maior destaque nos resultados de competições mundiais. Sendo assim, pode-se inferir que o universo das pesquisas e do avanço competitivo esteja relacionado, existindo na área o início de uma aproximação do fazer científico com o profissional.

Portanto, considera-se que o presente estudo pode apresentar uma contribuição para a comunidade acadêmica, apontando o modus operandi relativo à produção do conhecimento acerca da Ginástica Rítmica, incentivando uma maior produção sobre a temática nas suas diversas vertentes passíveis de investigação. Conclui-se que esse estudo oferece subsídios metodológicos práticos para ampliar o entendimento sobre o atual quadro da produção do conhecimento acerca da GR na América Latina, Caribe e países ibéricos e os dados apresentados, tal como a compreensão dos mesmos, o que pode contribuir como fomento de conhecimento. Afinal, compreende-se que com este escrito pode-se instigar os pesquisados interessados no tema para que iniciem novos estudos, principalmente no que se diz respeito às temáticas com menores incidências. Sinaliza-se também a necessidade prática, assim como afirma Lourenço (2003), de mais pesquisas que possam efetivamente contribuir com 0 trabalho daqueles que fazem a modalidade cotidianamente acontecer.

\section{Referências}

Álvarez, O., Falco, C., Estevan, I., Molina-García, J., \& Castillo, I. (2013). Intervención psicológica en un equipo de gimnasia rítmica deportiva: Estudio de un caso. Revista de Psicología del Deporte, 22(2), 395-401. Recuperado de http://www.redalyc.org/articulo.oa?id=235128058008

Amengual, M., \& Lleixà, T. (2011). La creatividad motriz en gimnasia rítmica deportiva en edad escolar. International Journal of Medicine and Science of Physical Activity and Sport, 11(43), 548-563. Recuperado de http://www.redalyc.org/articulo.oa?id=54222177007 
Arriaza, E., Rodríguez, C., Carrasco, C., Mardones, C., Niedmann, L., \& LópezFuenzalida, A. (2016). Anthropometric characteristics of elite rhythmic gymnasts. International Journal of Morphology, 34(1), 17-22. Recuperado de https://www.researchgate.net/publication/301205196 Anthropometric Characteristics of Elite Rhythmic Gymnasts

Belão, M., Machado, L. P., \& Mori, P. M. M. (2009). A formação profissional das técnicas de ginástica rítmica. Motriz rev. educ. fís.(Impr.), 15(1), 61-68. Recuperado de http://www.periodicos.rc.biblioteca.unesp.br/index.php/motriz/article/view/2139/2284

Bobo-Arce, M. \& Rial, B. M. (2013). Determinants of competitive performance in rhythmic gymnastics. A review. Journal of Human Sport and Exercise, 8(3), 711-727. Recuperado de http://www.redalyc.org/articulo.oa?id=301028375009

Boligon, L., Deprá, P. P., \& Rinaldi, I. P. B. (2015). Influence of flexibility in the ex ecution of movements in rhythmic gymnastics. Acta Scientiarum. Health Sciences, 37(2), 141-145. Recuperado de http://www.redalyc.org/articulo.oa?id=307242823005

Bosso, L. R., \& Golias, A. R. C. (2012). A postura de atletas de ginástica rítmica: análise através da fotometria. Revista Brasileira de Medicina do Esporte, 18(5), 333337. Recuperado de http://www.scielo.br/scielo.php?script=sci arttext\&pid=S1517$\underline{86922012000500010}$

Caçola, P. M., \& Ladewig, I. (2008). Comparação entre as práticas em partes e como um todo e a utilização de dicas na aprendizagem de uma habilidade da ginástica rítmica. Revista Brasileira de Ciência e Movimento, 15(4), 79-86. Recuperado de http://www.metaproducoes.com.br/artigos/treinamento/8.pdf

Cavalcanti, L. M. B., \& Porpino, K. O. (2015). O sofrimento e a dor como constituintes da beleza esportiva: reflexões para a educação. Holos, 5. Recuperado de http://www.redalyc.org/pdf/4815/481547288032.pdf

Coelho, S. M. H., Simões, R. D., \& Lunz, W. (2015). Desequilíbrio hormonal e disfunção menstrual em atletas de ginástica rítmica. Revista Brasileira de Ciências do 
Esporte, 37(3), 222-229. Recuperado de http://www.scielo.br/pdf/rbce/v37n3/01013289-rbce-37-03-0222.pdf

Costa, T. A., Gonçalves, H. R., Anschau, F. R., Viaro, L. F., Borgheti, R., dos Santos, F. B., \& Borges, J. H. (2017). Suplementação com bebida artesanal que contém carboidrato em atletas da ginástica rítmica. Revista Brasileira de Ciências do Esporte, 39(2), 115-122. Recuperado de http://www.scielo.br/pdf/rbce/v39n2/01013289-rbce-39-02-0115.pdf

Debien, P. B., Noce, F., Debien, J. B. P., \& da Costa, V. T. (2014). O estresse na arbitragem de ginástica rítmica: uma revisão sistemática. Journal of Physical Education, 25(3), 489-500. Recuperado de http://www.scielo.br/scielo.php?pid=S1983$\underline{30832014000300489 \& \text { script }=\text { sci abstract }}$

Del Vecchio, F. B., Primeira, M., Silva, H. C. D., Dall'agnol, C., \& Galliano, L. M. (2014). Nível de aptidão física de atletas de ginástica rítmica: Comparações entre categorias etárias. Revista brasileira de Ciência e Movimento, 22(3), 5-13. Recuperado de https://portalrevistas.ucb.br/index.php/RBCM/article/view/4444

Fontana, P.; Barbosa, M.; Balbinotti, M.; Balbinotti, C. (2013) Promoting artistic quality in rhythmic gymnastics: a didactic analysis from high performance to school practice. Pensar a Prática, 16, 320-618. Recuperado de http://www.scielo.br/scielo.php?script=sci arttext\&pid=S1807-55092016000100145

Garcia, C. C., Martrucelli, C. R. N., Rossilho, M. D. M. F., \& Denardin, O. V. P. (2010). Autoria em artigos científicos: os novos desafios. Revista Brasileira de Cirurgia Cardiovascular/Brazilian Journal of Cardiovascular Surgery, 25(4), 559-567. Recuperado de http://www.scielo.br/pdf/rbccv/v25n4/v25n4a21

Golias, A. R. C. (2012). Relação entre instabilidade do joelho e alterações posicionais do membro inferior de atletas de Ginástica Rítmica. Revista Brasileira de Ciência e Movimento, 20(2), 52-60. Recuperado em https://portalrevistas.ucb.br/index.php/RBCM/article/view/3153

Gonçalves, L. A. P., de Azevedo Barros Filho, A., \& Gonçalves, H. R. (2010). Características antropométricas de atletas de ginástica rítmica. Arquivos de Ciências 
da Saúde da UNIPAR, 14(1),

17-25.

Recuperado

em

http://revistas.unipar.br/index.php/saude/article/view/3399

Goulart, N. B. A., Dias, C. P., Lemos, F. D. A., Oliva, J. C., Lanferdini, F. J., \& Vaz, M. A. (2014). Evaluation of passive plantarflexion torque and active dorsiflexion torque in rhythmic gymnasts and nonathletes. Revista Brasileira de Educação Física e Esporte, 28(3), 371-376. Recuperado em http://www.scielo.br/scielo.php?script=sci arttext\&pid=S1807-55092014000300371

Ribeiro, D. G., Suárez, M. H., \& García-Manso, J. M. (2015). Efecto del entrenamiento sistemático de gimnasia rítmica sobre el control postural de niñas adolescentes. Revista andaluza de medicina del deporte, 8(2), 54-60. Recuperado em http://www.redalyc.org/articulo.oa?id=323338744002

Guiotte, V. A., Roque, C. F., de Oliveira, M. R., de Oliveira Gil, A. W., Rabello, L. M., Nobre dos Santos, E. V., ... \& da Silva, R. A. (2012). Avaliação físico-Funcional de Atletas da Ginástica Ritmica: História de Lesoes e Estabilidade Postural. UNOPAR Científica. Ciências Biológicas e da Saúde, 14(4), 217-220. Recuperado de http://www.pgsskroton.com.br/seer/index.php/JHealthSci/article/view/832

Hirata, A. C. D. S., \& Oliveira, R. F. D. (2016). Protocolo de treinamento proprioceptivo para atletas de Ginástica Rítmica-GR. ConScientiae Saúde, 14(4), 634-640. Recuperado de http://www.redalyc.org/pdf/929/92945642015.pdf

Karloh, M., Santos, R. P. D., Kraeski, M. H., Matias, T. S., \& Frutuoso, A. S. (2010). Alongamento estático versus conceito Mulligan-efeitos crônicos no treino de flexibilidade em ginastas. Rev Bras Cineantrop Desemp Hum, 12(3), 202-208. Recuperado de http://www.scielo.br/pdf/fm/v23n4/a03v23n4

Lamb, M., Oliveira, P. D. D., Tano, S. S., Gil, A. W. D. O., Santos, E. V. N. D., Fernandes, K. B. P., \& Oliveira, R. F. D. (2014). Efeito do treinamento proprioceptivo no equilíbrio de atletas de ginástica rítmica. Revista Brasileira de Medicina do Esporte, 20(5), 379-382. Recuperado de http://www.scielo.br/pdf/rbme/v20n5/15178692-rbme-20-05-00379.pdf

Lanaro Filho, P., \& Böhme, M. T. S. (2017). Detecção, seleção e promoção de talentos esportivos em ginástica rítmica desportiva: um estudo de revisão. Revista Paulista de 
Educação

Física, 15(2),

141-153.

Recuperado

de

http://www.revistas.usp.br/rpef/article/view/139898

Lemos, A., Chiviacowsky, S., Ávila, L. T. G., \& Drews, R. (2013). Efeitos do" feedback" autocontrolado na aprendizagem do lançamento da bola da ginástica rítmica. Revista Brasileira de Educação Física e Esporte, 27(3), 485-492. Recuperado de http://www.scielo.br/scielo.php?pid=S1807-

$\underline{55092013000300014 \& \text { script }=\text { sci } \text { abstract\&tlng }=\mathrm{pt}}$

Leta, J. Cruz, C. H. B. (2003) A produção cientifica brasileira. In: Viotti, Eduardo Baumgratz; Macedo, Mariano de Matos (Org.). Indicadores de Ciência, Tecnologia e Inovação no Brasil. Campinas: Editora Unicamp,p. 121-168.

Loquet, M. (2016). Promoting artistic quality in rhythmic gymnastics: a didactic analysis from high performance to school practice. Revista Brasileira de Educação Física e Esporte, 30(1),

145-158.

Recuperado

de

http://www.scielo.br/scielo.php?script=sci arttext\&pid=S1807-55092016000100145

Lourenço, M. R. A. (2003) Ginástica Rítmica no Brasil: a (r)evolução de um esporte. 154 f. Dissertação. Universidade Metodista de Piracicaba, Piracicaba. Recuperado de http://cev.org.br/biblioteca/ginastica-ritmica-brasil-revolucao-um-esporte/

Lourenço, M. R. A. (2015). A seleção brasileira de conjuntos de ginástica rítmica: perfil de ginastas e treinadoras, estrutura técnica e administrativa e o habitus construído. 180 f. Tese. Universidade Estadual de Maringá, Maringá. Recuperado de http://nourau.uem.br/nou-rau/document/?code=vtls000220788

Manoel, E. D. J., \& Carvalho, Y. M. D. (2011). Pós-graduação na educação física brasileira: a atração (fatal) para a biodinâmica. Educação e Pesquisa, vol. 37, núm. 2, mayo-agosto, 2011, pp. 389-406 Universidade de São Paulo São Paulo, Brasil. Educação e Pesquisa, 37(2), 389-406. Recuperado de http://www.scielo.br/scielo.php?pid=S1517-97022011000200012\&script=sci abstract\&tlng=pt

Mejías, N., \& María, J. (2013). Cambios de la técnica corporal en la modalidad de Gimnasia Rítmica. Códigos de puntuación 1993-2005. Revista de Investigación, 37(79), 101-118. Recuperado de http://revistas.upel.edu.ve/index.php/revinvest/article/view/3084 
Menezes, L. S.; Novaes, J.; Fernandes Filho, J. (2014). Somatotipo de atletas e praticantes de Ginástica Rítmica pré e pós-púberes. International Journal of Morphology , 32, 1025-1029. Recuperado de http://www.intimorphol.com/wpcontent/uploads/2015/06/art 36 323.pdf

Menezes, L. D. S., Novaes, J., \& Fernandes-Filho, J. (2012). Qualidades físicas de atletas e praticantes de Ginástica Rítmica pré e pós-púberes. Revista de Salud Pública, 14, 238-247. Recuperado de http://www.redalyc.org/articulo.oa?id=42225409004

Ramos, R. M., \& Velásquez, I. M. Á. (2006). Orientaciones metodológicas para desarrollar la preparación física (fuerza) en las atletas de gimnasia rítmica. Ra Ximhai: revista científica de sociedad, cultura y desarrollo sostenible, 2(2), 515-532. Recuperado de http://www.redalyc.org/articulo.oa?id=46120212

Nakashima, F. S., Junior, J. R. A. N., \& Vieira, L. F. (2012). O papel dos pais na trajetória esportiva de atletas de ginástica rítmica. Pensar a Prática, 15(4).821-1113. Recuperado de https://www.revistas.ufg.br/fef/article/view/14380

Oliveira, G. M., \& Porpino, K. D. O. (2010). Ginástica rítmica e educação física escolar: perspectivas críticas em discussão.13(2),116. Recuperado de https://www.revistas.ufg.br/fef/article/view/8632

Palacios de Espig, V., \& Sánchez Jaeger, A. (2016). Composición corporal y riesgo de trastorno de conducta alimentaria en atletas de gimnasia rítmica del Estado Carabobo. Salus, 20(3), $\quad$ 7-11. Recuperado de http://www.redalyc.org/pdf/3759/Resumenes/Resumen 375949531003 1.pdf

Penedo, T., Beltrao, F., \& Nunes, W. J. (2006). Análise da orientação espaço-temporal no desempenho motor competitivo em ginástica rítmica: Categorias pré-infantil e infantil. Fitness \& performance journal, (1), 44-49. Recuperado de http://www.fpjournal.org.br/painel/arquivos/7947\%200rientacao\%20na\%20GRD\%20Rev\%201\%202006\%20Portuques.pdf

Perin, A., Ulbricht, L., da Vinha Ricieri, D., \& Neves, E. B. (2012). Utilização da biofotogrametria para a avaliação da flexibilidade de tronco. Revista Brasileira de 
Medicina do Esporte, 18(3), 176-180. Recuperado de http://www.scielo.br/scielo.php?script=sci arttext\&pid=S1517-86922012000300008

Júnior, J. A. D. P., de Sousa, M. D. S. C., Gaya, A. C. A., \& Alves, J. V. D. M. H. (2012). Maturação biológica e desempenho físico de jovens atletas de ginástica rítmica. Revista Brasileira de Ciência e Movimento, 20(1), 88-96. Recuperado de https://portalrevistas.ucb.br/index.php/RBCM/article/view/2708

Rigo, L. C., Ribeiro, G. M., \& Hallal, P. C. (2012). Unidade na diversidade: desafios para a Educação Física no século XXI. Revista Brasileira de Atividade Física \& Saúde, 16(4), 339-345. Recuperado de rbafs.org.br/RBAFS/article/download/631/661/

Sampaio, D. F., \& Valentini, N. C. (2015). Iniciação esportiva em ginástica rítmica: abordagens tradicional e o clima de motivação para a maestria. Journal of Physical Education, 26(1), 1-10. Recuperado de http://www.periodicos.uem.br/ojs/index.php/RevEducFis/article/view/22382

San Mauro Martín, I., Cevallos, V., Pina Ordúñez, D., \& Garicano Vilar, E. (2016). Aspectos nutricionales, antropométricos y psicológicos en gimnasia rítmica. Nutrición Hospitalaria, 33(4), 865-871. Recuperado de http://scielo.isciii.es/scielo.php?script=sci arttext\&pid=S0212-16112016000400016

Sánchez, J. C. J., Márquez, J. C., \& Peralto, E. L. (2010). Evaluación y análisis de habilidades psicológicas relacionadas con el rendimiento deportivo en gimnastas de rítmica. Revista Iberoamericana de Psicología del Ejercicio y el Deporte, 5(1), 15-28. Recuperado de http://www.redalyc.org/articulo.oa?id=311126267002

Santos, A. B., Lebre, E., \& Carvalho, L. Á. (2016). Explosive power of lower limbs in rhythmic gymnastics athletes in different competitive levels. Revista Brasileira de Educação Física e Esporte, 30(1), 41-50. Recuperado de http://www.scielo.br/scielo.php?script=sci arttext\&pid=S1807-55092016000100041

Santos, E. V. N., Lourenço, M. R. A., \& Gaio, R. (2010). Composição coreográfica em ginástica rítmica: do compreender ao fazer. Jundiaí: Fontoura, 1, 127. Recuperado de https://periodicos.ufsc.br/index.php/motrivivencia/article/viewFile/21758042.2010v22n35p279/18096 
Shigaki, L., Rabello, L. M., Camargo, M. Z., da Costa Santos, V. B., de Oliveira Gil, A. W., de Oliveira, M. R., \& Macedo, C. D. S. G. (2013). Análise comparativa do equilíbrio unipodal de atletas de ginástica rítmica. Revista Brasileira de Medicina do Esporte, 19(2), 104-107. Recuperado de http://www.scielo.br/scielo.php?script=sci arttext\&pid=S1517-86922013000200006

Silva, J. M., de Oliveira, D. V., Leme, D. E. C., do Nascimento Júnior, J. R. A., \& Anversa, A. L. B. (2016). Influência do treinamento de flexibilidade e força muscular em atletas de ginástica rítmica. Saúde e Pesquisa, 9(2), 325-331. Recuperado de http://periodicos.unicesumar.edu.br/index.php/saudpesq/article/view/5217

Souza, D. L., Moraes, M., \& Moreira, T. S. O perfil da produção científica online em português relacionada às modalidades olímpicas e paralímpicas. Movimento, 22(4), 1105-1120. Recuperado de https://seer.ufrgs.br/Movimento/article/view/64591

Toledo, E. D., \& Antualpa, K. (2016). The appreciation of artistic aspects of the Code of Points in rhythmic gymnastics: an analysis of the last three decades. Revista Brasileira de Educação Física e Esporte, 30(1), 119-131. Recuperado de http://www.scielo.br/scielo.php?script=sci arttext\&pid=S1807-55092016000100119

Vernetta, M., Fernández, E., Bedoya, J. L., Landero, A. G., \& Oña, A. (2011). Estudio relacional entre el perfil morfológico y estima corporal en la selección andaluza de gimnasia rítmica deportiva. European Journal of Human Movement, (26), 77-92. Recuperado de http://www.redalyc.org/articulo.oa?id=274219446006

Vernetta, M., Montosa, I., \& López-Bedoya, J. (2016). Análisis de las lesiones deportivas en jóvenes practicantes de gimnasia rítmica de competición en categoría infantil. Revista Andaluza de Medicina del Deporte, 9(3), 105-109. Recuperado de http://scielo.isciii.es/scielo.php?script=sci abstract\&pid=S1888-75462016000300002

Vieira, L. F., Botti, M., \& Vieira, J. L. L. Ginástica rítmica: análise dos fatores competitivos motivadores e estressantes da Seleção Brasileira Juvenil. Acta Scientiarum. Health Sciences, 27(2), 207-215. Recuperado de http://periodicos.uem.br/ojs/index.php/ActaSciHealthSci/article/view/1419

Vieira, J. L. L., Amorim, H. Z., Vieira, L. F., Amorim, A. C., \& da Rocha, P. G. M. (2009). Distúrbios de atitudes alimentares e distorção da imagem corporal no contexto 
competitivo da ginástica rítmica Eating disorders and body image distortion in the rhythmic gymnastics competitive context. Revista Brasileira de Medicina do Esporte, 15(6), 410-414. Recuperado de http://www.scielo.br/scielo.php?script=sci arttext\&pid=S1517-86922009000700001

Vieira, L. F., Amorim, H. Z., Amorim, A. C., Rocha, P. G. M. D., \& Vieira, J. L. L. (2009). Distúrbios de atitudes alimentares e sua relação com o crescimento físico de atletas paranaenses de ginástica rítmica. Motriz rev. educ. fís.(Impr.), 15(3), 552-561. Recuperado de http://www.scielo.br/scielo.php?pid=S1517$86922009000700001 \&$ script=sci abstract\&tlng=pt 